\title{
Preservation solution impacts physiologic function and cellular viability of human saphenous vein graft
}

\author{
Eric S. Wise, M.D. ${ }^{1,+}$, Kyle M. Hocking, Ph.D. ${ }^{1,2}$, Susan Eagle, M.D. ${ }^{3}$, Tarek Absi, M.D..$^{4,1}$, \\ Padmini Komalavilas, Ph.D. ${ }^{4,1}$, Joyce Cheung-Flynn, Ph.D. ${ }^{1}$, and Colleen Brophy, M.D. ${ }^{4,1}$ \\ ${ }^{1}$ Department of Surgery, Vanderbilt University Medical Center, Nashville TN, USA \\ ${ }^{2}$ Department of Biomedical Engineering, Vanderbilt University Medical Center, Nashville TN, USA \\ ${ }^{3}$ Department of Cardiothoracic Anesthesiology, Vanderbilt University Medical Center, Nashville \\ TN, USA
}

${ }^{4}$ VA Tennessee Valley Healthcare System, Nashville TN, USA

\begin{abstract}
Introduction-Recent clinical data suggests intraoperative preservation of human saphenous vein (HSV) in normal saline is associated with vein graft failure. We evaluated the influence of several preservation media on acute physiologic function and cellular viability of HSV conduit.

Methods-Unprepared (UP) HSV obtained from coronary artery bypass graft patients was characterized on a muscle bath after two hour storage in Plasma-Lyte A, normal saline, University of Wisconsin solution, Celsior solution, autologous whole blood, or glutathione-ascorbic acid- Larginine (GALA) solution. Vascular smooth muscle contractility to depolarizing $\mathrm{KCl}$ and phenylephrine was assessed. The relaxation of phenylephrine-pre-contracted HSV to sodium nitroprusside and carbachol (endothelial-independent and -dependent relaxation, respectively) was also assessed. Cellular viability was determined via the methyl thiazolyl tetrazolium (MTT) assay. Rat aortae were used to assess the effect of $\mathrm{pH}$ during graft preservation on endothelial-dependent relaxation.
\end{abstract}

Results-Preservation of HSV in normal saline and autologous whole blood impaired contractile responses to $\mathrm{KCl}$ relative to UP tissues, while University of Wisconsin solution and Celsior solution preservation enhanced contractile responses $(P<.05)$. Relative to UP tissues, responses to phenylephrine were decreased with preservation in normal saline, while preservation in University of Wisconsin solution, Celsior solution and GALA all potentiated these responses $(P<.05)$. Only normal saline preservation impaired endothelial-independent relaxation $(P=.005)$. Preservation in

\footnotetext{
${ }^{\mathrm{t}}$ Corresponding author: Eric S. Wise, M.D., Department of Surgery, Vanderbilt University Medical Center, $116121^{\text {st }}$ Ave S, MCN T2111, Nashville, TN 37232-2730. (eric.s.wise@ vanderbilt.edu), Phone: (615) 322-5198 Fax: (615) 936-5988.

This manuscript was presented as a Quickshot presentation (Abstract \# ASC20150622) at the Academic Surgical Congress, February 3-5, 2015, Las Vegas NV.
}

Disclosures:

None of the authors have anything to disclose.

Publisher's Disclaimer: This is a PDF file of an unedited manuscript that has been accepted for publication. As a service to our customers we are providing this early version of the manuscript. The manuscript will undergo copyediting, typesetting, and review of the resulting proof before it is published in its final citable form. Please note that during the production process errors may be discovered which could affect the content, and all legal disclaimers that apply to the journal pertain. 
Plasma-Lyte A ( $P=.02)$, normal saline $(P=.002)$ and University of Wisconsin solution $(P=.02)$ led to impaired endothelial-dependent relaxation. Normal saline preservation led to a decreased MTT viability index relative to UP tissues $\left(0.021 \pm 0.002 \mathrm{mg}^{-1} 0.5 \mathrm{~mL}^{-1}\right.$ vs. $0.033 \pm 0.005 \mathrm{mg}^{-1} 0.5 \mathrm{~mL}^{-1}$; $P=.03)$. Endothelial function was impaired by acidic $\mathrm{pH}$ in rat aorta.

Conclusions-Normal saline preservation causes graft injury leading to impaired physiologic function and decreased viability of HSV. This harm to the conduit is mitigated by the use of buffered salt solutions as preservation media.

\section{Introduction}

The human saphenous vein (HSV) is the most widely used conduit in aortocoronary and peripheral bypasses. ${ }^{1}$ During typical intraoperative preparation, HSV is subject to a series of "back-table" manipulations. One such manipulation is preservation in a storage medium prior to implantation. Previous studies have suggested preservation in normal saline may harm vascular conduits and promote neointimal hyperplasia. ${ }^{2,} 3$ In 2014, Harskamp et al. retrospectively examined the influence of the preservation solution on vein graft failure using the large multi-center patient cohort from the Project of Ex-vivo Vein Graft Engineering via Transfection (PREVENT) IV trial. ${ }^{4}{ }^{5}$ Grafts were stratified by preservation solution into normal saline, buffered saline and autologous whole blood groups. Buffered saline-preserved grafts had one-year vein graft failure rates significantly lower than other two groups, and were associated with a lower risk of five-year death, myocardial infarction and secondary revascularization. ${ }^{5}$ Despite these findings, heparinized normal saline is still widely used in coronary artery bypass grafting $(\mathrm{CABG})$, and it is unclear what comprises an optimal HSV preservation solution. 5, 6

Impaired physiologic responses, as measured in a muscle bath, and decreased cellular viability represent acute tissue injury and have been shown to correlate with accelerated intimal growth. ${ }^{6,7}$ In this investigation, the influence of preservation solutions, including Plasma-Lyte A, normal saline, University of Wisconsin solution, Celsior solution, autologous whole blood and glutathione-ascorbic acid- L-arginine solution (GALA) on cellular physiology and viability was assessed. ${ }^{8}$ We hypothesized that normal saline preservation would be detrimental to vein graft physiologic function and viability, and this may be due to its acidity. These data may also provide insights into identifying the components of an HSV storage medium that enhance graft function.

\section{Methods}

\section{Materials and Reagents}

All chemicals were purchased from Sigma-Aldrich (St. Louis, MO) unless otherwise specified. University of Wisconsin solution, Celsior solution and GALA were prepared in the laboratory and sterile filtered prior to use.$^{8-10}$ The compositions of the various solutions are outlined in Table 1. Preservation solutions for all experiments contained 10 units $/ \mathrm{mL}$ unfractionated heparin; GALA contained 40 units $/ \mathrm{mL}^{8}$ 


\section{Procurement of Human Saphenous Vein (HSV)}

Unprepared (UP) HSV segments were collected from CABG patients after informed consent in accordance with Institutional Review Boards of the Vanderbilt University Medical Center and the VA Tennessee Valley Healthcare System, Nashville, TN. immediately after surgical dissection. Patient confidentiality was maintained in compliance with the Health Insurance Portability and Accountability Act. The segments were placed into heparinized (10 units/mL, Hospira) Plasma-Lyte A and taken to the laboratory promptly for testing. Approximately 15-30 minutes elapsed from procurement to placement in the appropriate solution. HSV preservation in Plasma-Lyte A over this length of warm ischemia time has been shown not to influence acute functional responses. ${ }^{6}$ Arterial autologous whole blood was collected from select patients for use as a preservation solution.

\section{Procurement of Rat Aortae}

Rat aortae were collected from euthanized Sprague Dawley rats $(n=13)$. Animal procedures followed study protocols approved by the Vanderbilt Institutional Animal Care and Use Committee and adhered to National Institute of Health guidelines for care and use of laboratory animals. Immediately after euthanasia, the descending thoracic and upper abdominal aorta was isolated via median sternotomy and dissection, placed in cold heparinized University of Wisconsin solution, and transported to the laboratory for immediate testing.

\section{Physiological measurements of HSV Smooth Muscle and Endothelial Function}

The segments were carefully dissected free of fat and connective tissue and cut into 1 to 2$\mathrm{mm}$ rings. Two rings were hung immediately (UP control), and remaining rings were placed in the preservation solutions normal saline, Plasma-Lyte A, University of Wisconsin solution, Celsior solution, GALA or autologous whole blood for two hours, at room temperature, prior to suspension in the muscle bath.

HSV rings were suspended in a muscle bath containing a bicarbonate buffer $(120 \mathrm{mM} \mathrm{NaCl}$, $4.7 \mathrm{mM}$ potassium chloride $(\mathrm{KCl}), 1.0 \mathrm{mM} \mathrm{MgSO}_{4}, 1.0 \mathrm{mM} \mathrm{NaH}_{2} \mathrm{PO}_{4}, 10 \mathrm{mM}$ glucose, 1.5 $\mathrm{mM} \mathrm{CaCl}_{2}$, and $25 \mathrm{mM} \mathrm{Na}_{2} \mathrm{HCO}_{3}, \mathrm{pH}$ 7.4) bubbled with $95 \% \mathrm{O}_{2}$ and $5 \% \mathrm{CO}_{2}$ at $37^{\circ} \mathrm{C}$. The rings were stretched to $4 \mathrm{~g}$ of tension, maintained at a resting tension of $1 \mathrm{~g}$ and equilibrated for $2 \mathrm{hr}{ }^{7,}{ }^{11}$ Force measurements were obtained using a Radnoti Glass Technology (Monrovia, CA) force transducer (159901A) interfaced with a PowerLab data acquisition system and Chart software (AD Instruments, Colorado Springs, CO). The rings were treated first with $110 \mathrm{mM}$ potassium chloride $(\mathrm{KCl}$, with equimolar replacement of $\mathrm{NaCl}$ in bicarbonate buffer) to depolarize and contract functionally viable smooth muscle cells, and the force generated was measured. Rings generating $₫ 0.025 \times 10^{5}$ Newtons $(\mathrm{N}) / \mathrm{m}^{2}$ were considered non-viable and were not used for further testing. ${ }^{12}$ Viable tissues were allowed to re-equilibrate in bicarbonate buffer for 30 minutes after $\mathrm{KCl}$ challenge, following which contractile response of HSV rings to a physiologic agonist, phenylephrine $(1-5 \mu \mathrm{M}$, dosed uniquely to each individual patient to obtain a contraction $50-80 \%$ that of $\mathrm{KCl}$ on UP tissue) was tested. Endothelial-dependent relaxation of HSV was measured by addition of carbachol $(0.5 \mu \mathrm{M})$, a cholinomimetic, and endothelial-independent relaxation, with sodium nitroprusside $(0.1 \mu \mathrm{M})$ to phenylephrine-pre-contracted tissues. 


\section{Determination of pH-Sensitivity of Endothelial Function in Rat Aortae}

Rat aortae were dissected free of muscle and connective tissue, and cut into 1-mm rings. Rings were either suspended immediately on the muscle bath (UP control), or placed in one of the following solutions: normal saline, Plasma-Lyte A or Plasma-Lyte A titrated with dilute $\mathrm{HCl}$ to $\mathrm{pH} 5.5,6.0,6.5$ and 7.0, for 2 hours at room temperature prior to suspension in the muscle bath. Endothelial function was determined by carbachol $(0.5 \mu \mathrm{M})$ challenge after pre-contraction with phenylephrine $(0.1 \mu \mathrm{M})$ as described above for HSV.

\section{MTT Assay}

Cellular viability was determined using the methyl thiazolyl tetrazolium (MTT) assay. ${ }^{13,} 14$ After two hour incubation in preservation solutions, rings were placed in $250 \mu \mathrm{L} 0.01 \%$ thiazolyl blue tetrazolium bromide in phosphate-buffered saline for an additional one hour at $37^{\circ} \mathrm{C}$. Rings were then transferred to $0.5 \mathrm{~mL}$ 2-ethoxyethanol for $24 \mathrm{~h}$. to dissolve the formazan dye synthesized by viable cell. Absorbance of the 2-ethoxyethanol with dissolved formazan dye was measured spectrophotometrically at wavelength $\lambda=570 \mathrm{~nm}$, and normalized to tissue mass. ${ }^{13}$

\section{Data analysis}

Contractile response was defined by stress, which was calculated using the force generated by the tissues. $\left[10^{5}\right.$ Newtons $\left.(\mathrm{N}) / \mathrm{m}^{2}\right]=$ force $(\mathrm{g}) \times 0.0987 /$ area, where area is equal to the wet weight $[(\mathrm{mg}) /$ length (mm at maximal length)] divided by 1.055$) .{ }^{7}$ Relaxation was measured as a percent change normalized to the maximal phenylephrine contraction. Measures of central tendency were reported as mean responses \pm standard error of the mean. Paired $t$-tests were conducted in order to determine the strength of evidence ( $P$ value) of each experiment. A $P$ value $<.05$ was considered statistically significant.

\section{Results}

\section{Effect of preservation solution on contractile responses in HSV}

Normal saline preservation led to decreased $\mathrm{KCl}$-induced stress relative to UP control tissue $\left(0.101 \pm 0.01\right.$ vs. $0.149 \pm 0.02 \times 10^{5} \mathrm{~N} / \mathrm{m}^{2}, \mathrm{n}=26, P=.001$; Figure $\left.1 \mathrm{~A}\right)$; this was also observed with preservation in autologous whole blood $\left(0.095 \pm 0.02\right.$ vs. $0.138 \pm 0.02 \times 10^{5} \mathrm{~N} / \mathrm{m}^{2}, \mathrm{n}=17$, $P=.004)$. UP tissue exhibited decreased stress relative to tissues preserved in University of Wisconsin solution $\left(0.153 \pm 0.02\right.$ vs. $\left.0.207 \pm 0.02 \times 10^{5} \mathrm{~N} / \mathrm{m}^{2}, \mathrm{n}=26, P=.02\right)$ and CEL $\left(0.148 \pm 0.02\right.$ vs. $\left.0.213 \pm 0.02 \times 10^{5} \mathrm{~N} / \mathrm{m}^{2}, \mathrm{n}=19, P=.006\right)$. In addition to UP, preservation in normal saline impaired $\mathrm{KCl}$-induced stress relative to tissues preserved in Plasma-Lyte A $\left(0.103 \pm 0.01\right.$ vs. $\left.0.158 \pm 0.02 \times 10^{5} \mathrm{~N} / \mathrm{m}^{2}, \mathrm{n}=24, P<.001\right)$, University of Wisconsin solution $\left(0.102 \pm 0.01\right.$ vs. $\left.0.203 \pm 0.02 \times 10^{5} \mathrm{~N} / \mathrm{m}^{2}, \mathrm{n}=25, P<.001\right)$, Celsior solution $(0.100 \pm 0.01$ vs. $\left.0.202 \pm 0.02 \times 10^{5} \mathrm{~N} / \mathrm{m}^{2}, \mathrm{n}=17, P<.001\right)$ and GALA $\left(0.084 \pm 0.02\right.$ vs. $0.119 \pm 0.02 \times 10^{5} \mathrm{~N} / \mathrm{m}^{2}$, $\mathrm{n}=11, P=.007)$.

Similar to $\mathrm{KCl}$, normal saline preservation led to decreased phenylephrine-induced stress relative to UP control tissue $\left(0.068 \pm 0.009\right.$ vs. $0.092 \pm 0.01 \times 10^{5} \mathrm{~N} / \mathrm{m}^{2}, \mathrm{n}=26, P=.05$; Figure 1B). UP tissue exhibited decreased phenylephrine-induced stress relative to tissues preserved in University of Wisconsin solution $\left(0.093 \pm 0.01\right.$ vs. $0.149 \pm 0.02 \times 10^{5} \mathrm{~N} / \mathrm{m}^{2}$, 
$\mathrm{n}=26, P=.004)$, Celsior solution $\left(0.087 \pm 0.01\right.$ vs. $\left.0.144 \pm 0.02 \times 10^{5} \mathrm{~N} / \mathrm{m}^{2}, \mathrm{n}=18, P=.006\right)$ and GALA $\left(0.058 \pm 0.01\right.$ vs. $\left.0.083 \pm 0.01 \times 10^{5} \mathrm{~N} / \mathrm{m}^{2}, \mathrm{n}=11, P<.001\right)$. In addition to UP, preservation in normal saline impaired phenylephrine-induced stress relative to those tissues preserved in Plasma-Lyte A $\left(0.069 \pm 0.01\right.$ vs. $\left.0.107 \pm 0.01 \times 10^{5} \mathrm{~N} / \mathrm{m}^{2}, \mathrm{n}=23, P<.001\right)$, University of Wisconsin solution $\left(0.070 \pm 0.01\right.$ vs. $\left.0.142 \pm 0.02 \times 10^{5} \mathrm{~N} / \mathrm{m}^{2}, \mathrm{n}=25, P<.001\right)$, Celsior solution $\left(0.064 \pm 0.01\right.$ vs. $\left.0.131 \pm 0.02 \times 10^{5} \mathrm{~N} / \mathrm{m}^{2}, \mathrm{n}=16, P<.001\right)$ and GALA $\left(0.055 \pm 0.01\right.$ vs. $\left.0.083 \pm 0.01 \times 10^{5} \mathrm{~N} / \mathrm{m}^{2}, \mathrm{n}=11, P=.005\right)$. A representative force vs. time tracing is shown in Figure 1C.

\section{Effect of preservation solution on endothelial-independent relaxation in HSV}

Normal saline-preserved tissues exhibited decreased endothelial-independent relaxation relative to UP $(59.8 \pm 4.5 \%$ vs. $68.2 \pm 4.8 \%, \mathrm{n}=20, P=.005$; Figure $2 \mathrm{~A})$. Tissue preserved in Celsior solution exhibited significantly greater endothelial-independent relaxation relative to preservation in Plasma-Lyte A $(70.4 \pm 6.3 \%$ vs. $56.5 \pm 6.4 \%, \mathrm{n}=12, P<.001)$, normal saline (73.3 $\pm 5.3 \%$ vs. $58.3 \pm 5.7 \%, \mathrm{n}=15, P=.001)$, University of Wisconsin solution $(73.2 \pm 4.9 \%$ vs. $60.2 \pm 5.4 \%, \mathrm{n}=16, P=.01)$ and GALA $(76.5 \pm 7.4 \%$ vs. $62.2 \pm 6.9 \%, \mathrm{n}=8, P=.01)$.

\section{Effect of preservation solution on endothelial-dependent relaxation in HSV}

Normal saline-preserved tissues exhibited decreased endothelial-dependent relaxation relative to UP ( $10.8 \pm 1.9 \%$ vs. $24.2 \pm 3.2 \%, \mathrm{n}=17, P=.001$; Figure $2 \mathrm{~B})$. This was also observed with tissues preserved in Plasma-Lyte A $(19.3 \pm 2.2 \%$ vs. $28.3 \pm 3.4 \%, \mathrm{n}=13, P=.02)$ and University of Wisconsin solution $(15.3 \pm 2.1 \%$ vs. $23.4 \pm 3.4 \%, \mathrm{n}=16, P=.02)$. In addition to UP, preservation in normal saline impaired endothelial-dependent relaxation relative to Plasma-Lyte A $(10.2 \pm 2.1 \%$ vs. $19.4 \pm 1.9 \%, \mathrm{n}=15, P<.001)$, University of Wisconsin solution $(8.6 \pm 1.7 \%$ vs. $17.9 \pm 2.5 \%, \mathrm{n}=16, P=.005)$, autologous whole blood $(11.5 \pm 3.1 \%$ vs. $26.7 \pm 3.3 \%, \mathrm{n}=9, P=.02)$ and GALA $(11.4 \pm 2.8 \%$ vs. $19.9 \pm 1.2 \%, \mathrm{n}=8, P=.02)$. Tissues preserved in autologous whole blood demonstrated greater endothelial dependent relaxation relative to tissue preserved in University of Wisconsin solution $(27.7 \pm 3.9 \%$ vs. $12.7 \pm 2.6 \%$, $\mathrm{n}=7, P=.007)$, Celsior $(25.7 \pm 5.4 \%$ vs. $16.0 \pm 3.7 \%, \mathrm{n}=5, P=.02)$ and GALA $(30.3 \pm 3.0 \%$ vs. $19.7 \pm 1.7 \%, \mathrm{n}=6, P=.03)$. A representative force vs. time tracing is shown in Figure $2 \mathrm{C}$.

Physiologic functional performance of HSV preserved in various media relative to UP tissue is summarized in Table 2.

\section{Effect of preservation solution on cell viability in HSV}

Because cellular viability correlates with functional viability in $\mathrm{HSV},{ }^{12}$ we next compared the cellular viability of HSV $(n=11)$ after storage in the preservation solutions. UP control tissue had greater cellular viability $\left(0.033 \pm 0.005 \mathrm{mg}^{-1} 0.5 \mathrm{~mL}^{-1}\right)$ relative to tissue preserved in normal saline $\left(0.021 \pm 0.002 \mathrm{mg}^{-1} 0.5 \mathrm{~mL}^{-1}, P=.03\right.$; Figure 3$)$. In addition, tissues preserved in normal saline had decreased cellular viability relative to tissues preserved in Plasma-Lyte A $\left(0.028 \pm 0.004 \mathrm{mg}^{-1} 0.5 \mathrm{~mL}^{-1}, P=.03\right)$, University of Wisconsin solution $\left(0.045 \pm 0.007 \mathrm{mg}^{-1} 0.5 \mathrm{~mL}^{-1}, P=.003\right)$ and autologous whole blood $\left(0.035 \pm 0.005 \mathrm{mg}^{-1} 0.5\right.$ $\left.\mathrm{mL}^{-1}, P=.01\right)$. University of Wisconsin solution-preserved HSV also demonstrated improved cellular viability relative to preservation in Plasma-Lyte A $(P=.02)$ and Celsior $(P=.006)$. 


\section{Influence of pH on Endothelial-Dependent Relaxation in Rat Aortae}

Because preservation in buffered solution appeared to be superior to normal saline, we hypothesized that maintenance of $\mathrm{pH}$ was vital to physiologic function and cellular viability of HSV. The rat aorta was used as a model system of normal vascular tissue with which the influence of $\mathrm{pH}$ on endothelial function could be measured. Relative to control rat aorta, endothelial function was decreased in tissues preserved in normal saline $(39.0 \pm 4.7 \%$ vs. $27.6 \pm 4.2 \%, \mathrm{n}=11, P=.02$; Figure 4$)$ and $\mathrm{pH}$ 5.5-Plasma-Lyte A (39.0 $\pm 4.7 \%$ vs. $23.6 \pm 6.7 \%$, $\mathrm{n}=11, P=.01)$. Relative to rat aorta preserved in Plasma-Lyte A, endothelial function was decreased in tissues preserved in normal saline $(40.2 \pm 8.2 \%$ vs. $27.6 \pm 4.2 \%, \mathrm{n}=10, P=.04)$ and $\mathrm{pH}$ 5.5-Plasma-Lyte A ( $42.0 \pm 7.1 \%$ vs. $23.6 \pm 6.7 \%, \mathrm{n}=10, P=.003)$. Relative to rat aorta preserved in $\mathrm{pH}$ 7.0-Plasma-Lyte A, endothelial function was decreased in tissues preserved in normal saline $(41.5 \pm 7.1 \%$ vs. $27.6 \pm 4.2 \%, \mathrm{n}=11, P=.04)$ and $\mathrm{pH} 5.5$-Plasma-Lyte A $(41.5 \pm 7.1 \%$ vs. $23.6 \pm 6.7 \%, \mathrm{n}=11, P=.02)$. No significant differences were noted in rat aorta endothelial function among tissues preserved in the range $6.0 £ \mathrm{pH}<7.0$.

\section{Discussion}

Grafting with HSV conduit represents an autologous transplantation, as it is explanted, prepared on the "back-table" and then implanted into the arterial system. However, in contrast to other solid organs used for allotransplantation, the graft generally is afforded suboptimal treatment with respect to preservation medium. For example, University of Wisconsin preservation solution was developed in the 1980s specifically for use with pancreas grafts, and contained free radical scavengers, buffering anions as well as sugars and colloid to reduce cellular swelling. Due to its early success in pancreas preservation, use of University of Wisconsin solution was soon translated to liver, kidney and other solid organs as well. ${ }^{9}, 15,16$ Additionally, Celsior solution was designed specifically for the preservation of heart allografts. Conversely, HSV is currently preserved in normal saline at approximately $40 \%$ of centers, despite evidence of its harm. ${ }^{5,6}$

The detrimental effects of normal saline were recognized as early as 1974, as O'Connell et al. demonstrated that 2-3 hours of saline infusion produced increased myointimal proliferation and obliteration one month postoperatively, relative to serum-infused control, in a rabbit carotid artery model. ${ }^{2}$ Santoli et al. used University of Wisconsin solution as an HSV preservation medium, and compared several additional solutions histologically. Electron microscopy demonstrated that preservation in autologous whole blood led to endothelial damage and detachment, and medial edema. Normal saline partially preserved endothelial integrity at 30 minutes, but few surviving cells were noted after 5 hours. There were no significant structural endothelial alterations in University of Wisconsin-preserved tissue at either 30 minutes or 5 hours of preservation. ${ }^{17}$ Tsakok et al. evaluated eleven studies' to determine if normal saline or autologous whole blood was more effective in graft preservation. It was concluded that room-temperature saline was detrimental to vascular endothelium, and both normal saline and autologous whole blood impair smooth muscle function, relative to a buffered saline solution such as University of Wisconsin solution. ${ }^{18}$

It has been only recently that solutions have been designed specifically for vascular conduit preservation. ${ }^{19,20}$ GALA, as the most widely recognized of these solutions, was used for 
physiologic characterization along with more traditional solutions. GALA contains glutathione and L-ascorbic acid, antioxidants, and arginine, a substrate for nitric oxide synthase in endothelial cells, which were added to a buffered electrolyte solution. ${ }^{8}$ GALA solution, and other transplant harvest solutions have not previously been directly compared to normal saline using HSV tissue.

Our results indicate foremost that normal saline preservation caused acute cellular injury to HSV. HSV stored in normal saline demonstrated impaired contractility in response to $\mathrm{KCl}$ depolarization and phenylephrine-induced contraction. Impaired smooth muscle responses were observed not only upon treatment with exogenous donor sodium nitroprusside, but also upon treatment with carbachol, a cholinomimetic inducer of endothelial nitric oxide production. These findings were associated with a concomitant reduction in cellular viability, as indicated by the MTT assay. Normal saline is not buffered and therefore prone to acidification by ambient carbon dioxide, leading to a non-physiologic $\mathrm{pH}<6$. In fact, its clinical systemic use has led to an association with hyperchloremic metabolic acidosis, as well as increased renal dysfunction and infection. ${ }^{21}$ Our mechanistic data, using rat aorta as a model system, suggested an endothelial functional dependence on $\mathrm{pH}$, with potentiation of dysfunction particularly below the 6-7 range. As normal saline was the only non-buffered solution, these data offer insight into the mechanism of endothelial injury manifested by normal saline-preserved tissues.

While normal saline preservation impaired vasoconstriction, University of Wisconsin solution and Celsior solution preservation led to vigorous smooth muscle contraction, significantly greater than that seen in UP control. Both University of Wisconsin solution and Celsior solution contained supraphysiologic concentrations of potassium. ${ }^{9}, 10$ Preservation in these potassium-rich media may promote greater contractions due to the depolarization caused by potassium. A high potassium environment would likely not represent a desirable quality in a vascular graft preservation solution, as the potassium has potential to persist in the tissue and lead to vasospasm.

Endothelial preservation in HSV graft is critically important in the perioperative period. Once arterialized, a denuded luminal surface presents a nidus for platelet or leukocyte interaction with the vessel wall, promoting thrombogenesis. ${ }^{19}$ Furthermore, endothelial injury leads to enhanced medial smooth muscle proliferation and migration, as well as activation of a cascade of mediators governing inflammation and oxidative stress, resulting in accelerated intimal hyperplasia. ${ }^{1,22-24}$ In this investigation, storage in all solutions except autologous whole blood and GALA led to a decrease in endothelial-dependent relaxation compared to UP control. Autologous whole blood preservation exposed the fragile endothelium to a minimally perturbed microenvironment where it was exposed to the same composition of growth factors, proteins and electrolytes as in vivo. GALA solution preservation led to preserved endothelial responses possibly due to the inclusion of nitric oxide synthase substrate arginine.

While response to carbachol reflected both endothelial nitric oxide release and the response of smooth muscle, response to sodium nitroprusside represented a functional assessment of smooth muscle tissue exclusively. Preservation in Celsior solution led to optimal smooth 
muscle responsiveness. This could possibly be due to the combination of the beneficial effect of a nutrient-rich media, without exposure to the elevated potassium concentration of University of Wisconsin solution, which may promote a phenotype of resistance to relaxation. While the other preservation media did not fare as well as UP control in response to sodium nitroprusside, only those tissues preserved in normal saline demonstrated a statistically significant decrement in endothelial-independent relaxation.

Taken together, these data suggest that preservation in a buffered electrolyte solution with a physiologic $\mathrm{pH}$ is critical to maintain functional integrity of HSV during storage. University of Wisconsin solution, containing cellular nutrients and antioxidants among other additives, fared well in both functional and viability assays. Antioxidant additives such as glutathione or ascorbic acid can prevent free radical generation which may be associated with preparation induced injury, ${ }^{6}$ however it remains uncertain whether the use of antioxidants would enhance vein graft function and patency. ${ }^{25}$ Plasma-Lyte A preservation of HSV also performed well, with no significant decrement relative to UP tissue in any of the functional and viability assays performed. As an HSV preservation medium, a simple buffered salt solution such as Plasma-Lyte A appeared no less effective, yet far more cost efficient than University of Wisconsin solution, Celsior solution and GALA.

Recently, we reported the effects of vascular cell $\mathrm{P} 2 \mathrm{X}_{7}$ receptor antagonist brilliant blue FCF, a non-toxic water soluble food dye, on HSV tissue. ${ }^{7,26}$ The addition of $50 \mu \mathrm{M}$ brilliant blue FCF to Plasma-Lyte A improved endothelial-dependent relaxation in UP HSV and prevented intimal growth in HSV in an organ culture model and a rabbit model of vein grafting. ${ }^{27}$ These beneficial effects of brilliant blue FCF, lack of cellular toxicity and distinct blue color make it attractive as an additive to an HSV preservation solution. ${ }^{7}$ Our experiments were not sufficiently broad in scope to discern which additives in Celsior and University of Wisconsin solution most influenced graft performance. While it is clear that the use of a buffered balanced salt solution is ideal for conduit preservation, more work is needed to determine the role of specific additives besides brilliant blue FCF in providing further enhancement of vein graft function.

This study has several limitations. First, samples of UP tissue were obtained from the operating rooms of various surgical teams, each using slightly different methods of HSV harvest. While great care was taken in UP HSV procurement and preparation for use in experiments, tissue manipulations including stretching, and injury from dissection and cleaning of the graft led to non-uniform handling. The advantage of this approach, however, was that tissue designated for use on actual surgical patients was obtained for these experiments. Second, our data reflect only acute physiologic responses of HSV and tissue viability in a MTT assay. In addition to the evidence provided by Harksamp et al., other laboratory-based studies have demonstrated a direct correlation between diminished HSV physiologic function and accelerated intimal growth in organ culture. ${ }^{5-7,28}$ Nonetheless, in vivo assessment of the effect of preservation solution on neointimal hyperplasia is necessary to determine if there is a direct correlation with vein graft failure. Finally, while $\mathrm{pH}$ appears to promote endothelial dysfunction, the mechanism that underlies the harmful effects of normal saline may be more complex, and include its mild hyperosmolarity, lack of cellular nutrients and lack of antioxidants. 
In conclusion, intraoperative preparation of HSV on the "back-table" creates an important window during which appropriate ex vivo storage of the graft can mitigate acute injury. Use of NS preservation impairs physiologic function and decreases cellular viability of the graft. The optimal preservation medium is unknown; however, use of a balanced, buffered salt solution, potentially with additives such as arginine, $\mathrm{P} 2 \mathrm{X}_{7}$ receptor antagonists, antioxidants or cellular nutrients, can maintain smooth muscle function and viability, as well as an intact, functional endothelial monolayer.

\section{Acknowledgments}

The authors thank the cardiac surgery attendings, physician assistants and intraoperative nursing staff at Vanderbilt University and the Nashville VA for assistance in vein collection.

This study was supported in part with resources and materials from the VA Tennessee Valley Healthcare System; NIH R01HL70715-09 and a Biomedical Laboratory Research and Development Grant to CB for design and conduct of the study, collection, management, analysis, and interpretation of the data, and drafting and approval of the manuscript; and NIH R01HL105731-01A1 to JC for design and conduct of the study; collection, management, analysis, and interpretation of the data; and preparation, drafting and approval of the manuscript.

\section{References}

1. Hussaini BE, Lu XG, Wolfe JA, Thatte HS. Evaluation of endoscopic vein extraction on structural and functional viability of saphenous vein endothelium. Journal of cardiothoracic surgery. 2011; 6:82. [PubMed: 21663646]

2. O'Connell TX, Sanchez M, Mowbray JF, Fonkalsrud EW. Effects on arterial intima of saline infusions. The Journal of surgical research. 1974; 16:197-203. [PubMed: 4819609]

3. Cavallari N, Abebe W, Mingoli A, Hunter WJ 3rd, Agrawal DK, Sapienza P, et al. Functional and morphological evaluation of canine veins following preservation in different storage media. The Journal of surgical research. 1997; 68:106-15. [PubMed: 9184668]

4. Lopes RD, Williams JB, Mehta RH, Reyes EM, Hafley GE, Allen KB, et al. Edifoligide and longterm outcomes after coronary artery bypass grafting: PRoject of Ex-vivo Vein graft ENgineering via Transfection IV (PREVENT IV) 5-year results. American heart journal. 2012; 164:379-86. e1. [PubMed: 22980305]

5. Harskamp RE, Alexander JH, Schulte PJ, Brophy CM, Mack MJ, Peterson ED, et al. Vein graft preservation solutions, patency, and outcomes after coronary artery bypass graft surgery: follow-up from the PREVENT IV randomized clinical trial. JAMA surgery. 2014; 149:798-805. [PubMed: 25073921]

6. Osgood MJ, Hocking KM, Voskresensky IV, Li FD, Komalavilas P, Cheung-Flynn J, et al. Surgical vein graft preparation promotes cellular dysfunction, oxidative stress, and intimal hyperplasia in human saphenous vein. Journal of vascular surgery. 2014; 60:202-11. [PubMed: 23911244]

7. Voskresensky IV, Wise ES, Hocking KM, Li FD, Osgood MJ, Komalavilas P, et al. Brilliant blue FCF as an alternative dye for saphenous vein graft marking: effect on conduit function. JAMA surgery. 2014; 149:1176-81. [PubMed: 25251505]

8. Thatte HS, Biswas KS, Najjar SF, Birjiniuk V, Crittenden MD, Michel T, et al. Multi-photon microscopic evaluation of saphenous vein endothelium and its preservation with a new solution, GALA. The Annals of thoracic surgery. 2003; 75:1145-52. discussion 52. [PubMed: 12683553]

9. Southard JH, Belzer FO. Organ preservation. Annual review of medicine. 1995; 46:235-47.

10. Menasche P, Termignon JL, Pradier F, Grousset C, Mouas C, Alberici G, et al. Experimental evaluation of Celsior, a new heart preservation solution. European journal of cardio-thoracic surgery: official journal of the European Association for Cardio-thoracic Surgery. 1994; 8:207-13. [PubMed: 8031565]

11. Li FD, Sexton KW, Hocking KM, Osgood MJ, Eagle S, Cheung-Flynn J, et al. Intimal thickness associated with endothelial dysfunction in human vein grafts. The Journal of surgical research. 2013; 180:e55-62. [PubMed: 22763213] 
12. Hocking KM, Brophy C, Rizvi SZ, Komalavilas P, Eagle S, Leacche M, et al. Detrimental effects of mechanical stretch on smooth muscle function in saphenous veins. Journal of vascular surgery. 2011; 53:454-60. [PubMed: 21146345]

13. Mosmann T. Rapid colorimetric assay for cellular growth and survival: application to proliferation and cytotoxicity assays. Journal of immunological methods. 1983; 65:55-63. [PubMed: 6606682]

14. Berridge MV, Tan AS. Characterization of the cellular reduction of 3-(4,5-dimethylthiazol-2yl)-2,5-diphenyltetrazolium bromide (MTT): subcellular localization, substrate dependence, and involvement of mitochondrial electron transport in MTT reduction. Archives of biochemistry and biophysics. 1993; 303:474-82. [PubMed: 8390225]

15. Southard JH. Improving early graft function: role of preservation. Transplantation proceedings. 1997; 29:3510-1. [PubMed: 9414814]

16. Muhlbacher F, Langer F, Mittermayer C. Preservation solutions for transplantation. Transplantation proceedings. 1999; 31:2069-70. [PubMed: 10455972]

17. Santoli E, Di Mattia D, Boldorini R, Mingoli A, Tosoni A, Santoli C. University of Wisconsin solution and human saphenous vein graft preservation: preliminary anatomic report. European journal of cardio-thoracic surgery: official journal of the European Association for Cardio-thoracic Surgery. 1993; 7:548-52. [PubMed: 8267997]

18. Tsakok M, Montgomery-Taylor S, Tsakok T. Storage of saphenous vein grafts prior to coronary artery bypass grafting: is autologous whole blood more effective than saline in preserving graft function? Interactive cardiovascular and thoracic surgery. 2012; 15:720-5. [PubMed: 22753436]

19. Wilbring M, Tugtekin SM, Zatschler B, Ebner A, Reichenspurner H, Matschke K, et al. Even short-time storage in physiological saline solution impairs endothelial vascular function of saphenous vein grafts. European journal of cardio-thoracic surgery: official journal of the European Association for Cardio-thoracic Surgery. 2011; 40:811-5. [PubMed: 21376620]

20. Kay MD, Hosgood SA, Harper SJ, Bagul A, Waller HL, Nicholson ML. Normothermic versus hypothermic ex vivo flush using a novel phosphate-free preservation solution (AQIX) in porcine kidneys. The Journal of surgical research. 2011; 171:275-82. [PubMed: 20421110]

21. Magder S. Balanced versus unbalanced salt solutions: what difference does it make? Best practice \& research Clinical anaesthesiology. 2014; 28:235-47. [PubMed: 25208959]

22. Soyombo AA, Angelini GD, Bryan AJ, Jasani B, Newby AC. Intimal proliferation in an organ culture of human saphenous vein. The American journal of pathology. 1990; 137:1401-10. [PubMed: 2260628]

23. Lee T, Roy-Chaudhury P. Advances and new frontiers in the pathophysiology of venous neointimal hyperplasia and dialysis access stenosis. Advances in chronic kidney disease. 2009; 16:329-38. [PubMed: 19695501]

24. Soyombo AA, Angelini GD, Bryan AJ, Newby AC. Surgical preparation induces injury and promotes smooth muscle cell proliferation in a culture of human saphenous vein. Cardiovascular research. 1993; 27:1961-7. [PubMed: 8287404]

25. Weaver H, Shukla N, Ellinsworth D, Jeremy JY. Oxidative stress and vein graft failure: a focus on NADH oxidase, nitric oxide and eicosanoids. Current opinion in pharmacology. 2012; 12:160-5. [PubMed: 22503078]

26. Peng W, Cotrina ML, Han X, Yu H, Bekar L, Blum L, et al. Systemic administration of an antagonist of the ATP-sensitive receptor P2X7 improves recovery after spinal cord injury. Proceedings of the National Academy of Sciences of the United States of America. 2009; 106:12489-93. [PubMed: 19666625]

27. Osgood MJ, Sexton KW, Voskresensky IV, Hocking KM, Song J, Komalavilas P, et al. Use of Brilliant Blue FCF During Vein Graft Preparation Inhibits Intimal Hyperplasia. Journal of vascular surgery. 2015

28. Li FD, Eagle S, Brophy C, Hocking KM, Osgood M, Komalavilas P, et al. Pressure control during preparation of saphenous veins. JAMA surgery. 2014; 149:655-62. [PubMed: 24759942] 

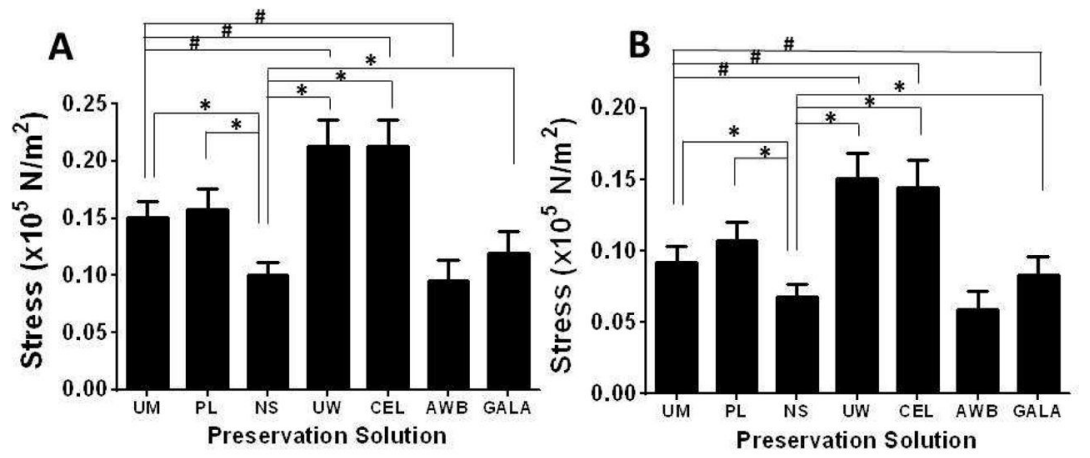

C

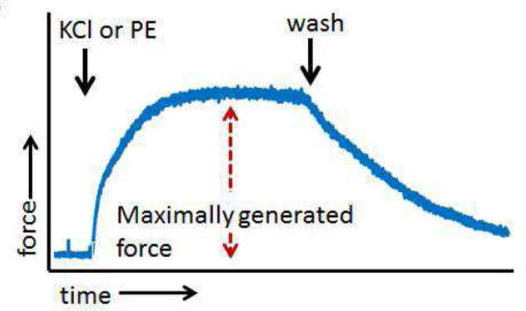

Figure 1.

Contractile Responses of HSV. A- Responses to $\mathrm{KCl}(110 \mathrm{mM}) . * P<.01$ relative to normal saline; ${ }^{\#} P<.05$ relative to UP. B- Responses to phenylephrine $(1-5 \mu \mathrm{M}) . * P<.05$ relative to normal saline; ${ }^{\#} P<.05$ relative to UP (all significantly greater than UP). Error bars represent standard error of the mean. C- Representative tracing of force vs. time plots generated by the muscle bath apparatus in response challenge with $\mathrm{KCl}$ or phenylephrine. A suspended ring of vascular tissue undergoes viscoelastic vasoconstriction. Maximum contraction is sustained until the tissue is washed with bicarbonate buffer and re-equilibrated (dotted arrow).

UP- Unprepared Control; PL- Plasma-Lyte A; NS- normal saline; UW- University of Wisconsin solution; CEL- Celsior solution; AWB- autologous whole blood; GALAglutathione-ascorbic acid- L-arginine solution; KCL- potassium chloride (110 mM); PEphenylephrine $(1-5 \mu \mathrm{M})$. 

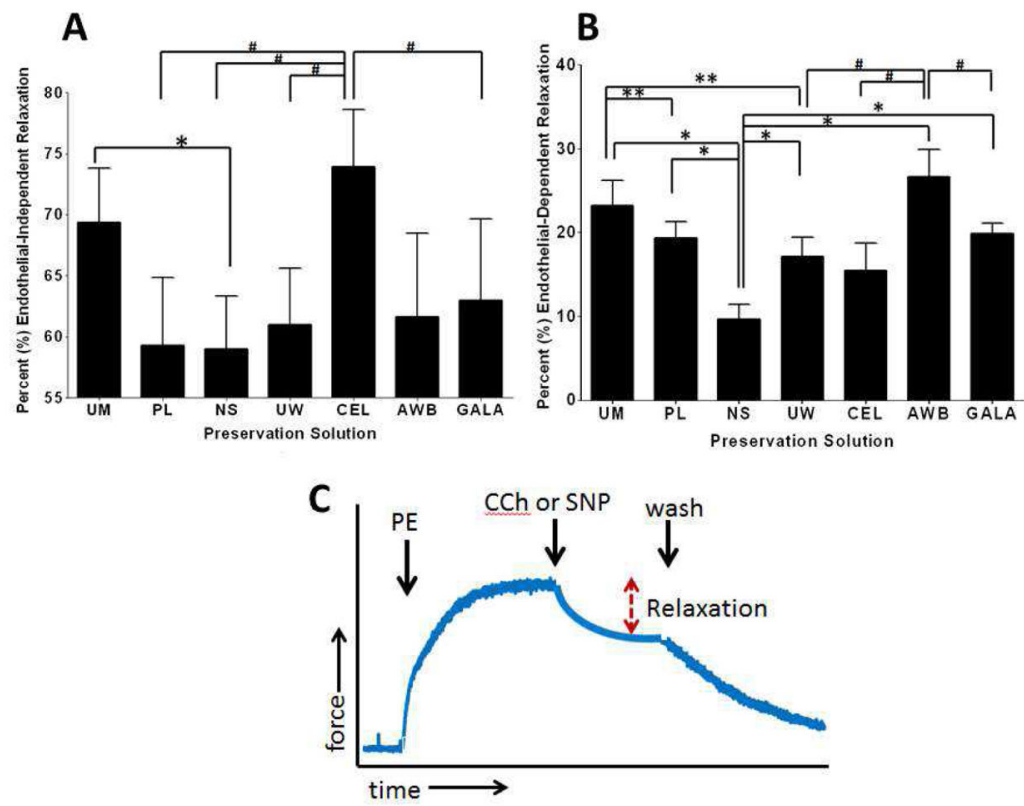

Figure 2.

Functional Relaxation Responses of HSV. A- Endothelial-Independent Smooth Muscle Relaxation ( $0.1 \mu \mathrm{M}$ sodium nitroprusside) of $\mathrm{HSV} .{ }^{*} P=.005 ;{ }^{*} P<.02$ relative to Celsior solution. Error bars represent standard error of the mean. B- Endothelial-Dependent Smooth Muscle Relaxation $(0.5 \mu \mathrm{M}$ carbachol) of HSV. $* P<.05$ relative to normal saline; $* * P<.05$ relative to UP; ${ }^{\#} P<.05$ relative to autologous whole blood. Error bars represent standard error of the mean. C- Representative tracing of force vs. time plots generated by the muscle bath apparatus in response to relaxation with carbachol or sodium nitroprusside after phenylephrine pre-contraction. Relaxation is characterized by the percent decrement from the phenylephrine-generated force (dotted arrow).

UP- Unprepared Control; PL- Plasma-Lyte A; NS- normal saline; UW- University of Wisconsin solution; CEL- Celsior solution; AWB- autologous whole blood; GALAglutathione-ascorbic acid- L-arginine solution; PE- phenylephrine (1-5 $\mu \mathrm{M})$; CChcarbachol $(0.5 \mu \mathrm{M})$; SNP- sodium nitroprusside $(0.1 \mu \mathrm{M})$. 


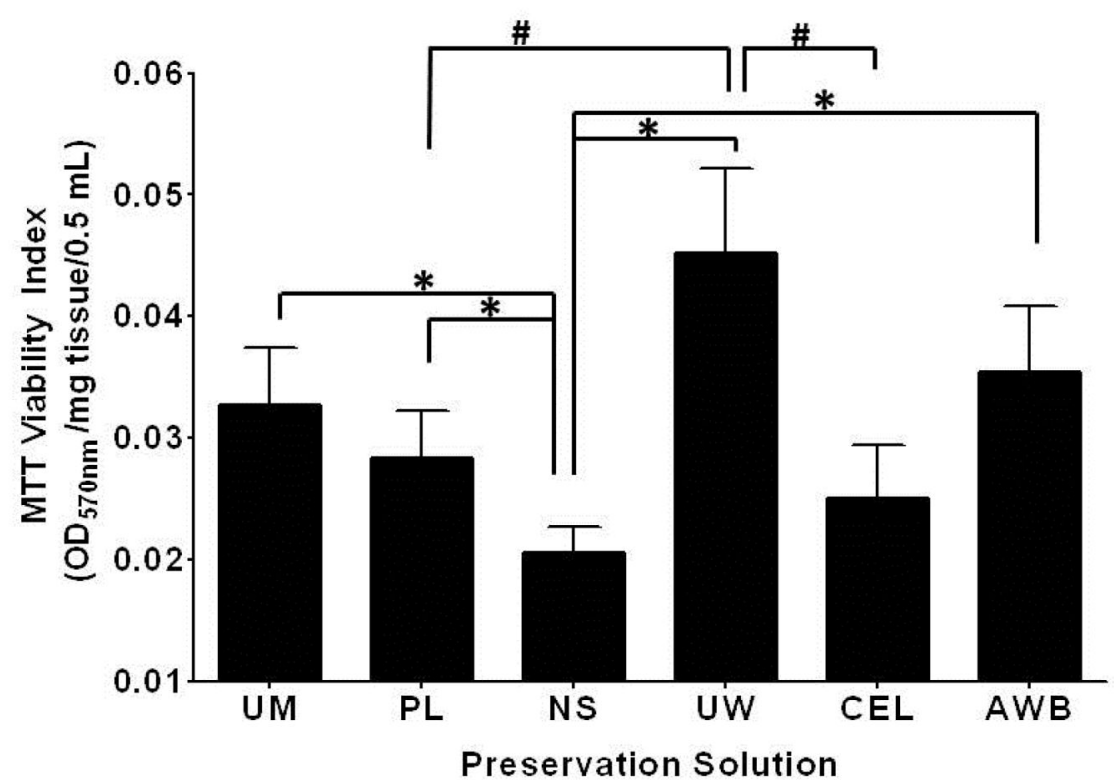

Figure 3.

MTT Cellular Viability Assay of HSV. $* P<.05$ relative to normal saline; ${ }^{*} P<.05$ relative to University of Wisconsin solution. Error bars represent standard error of the mean. UP- Unprepared Control; PL- Plasma-Lyte A; NS- normal saline; UW- University of Wisconsin solution; CEL- Celsior solution; AWB- autologous whole blood; GALAglutathione-ascorbic acid- L-arginine solution; MTT- methyl thiazolyl tetrazolium. 


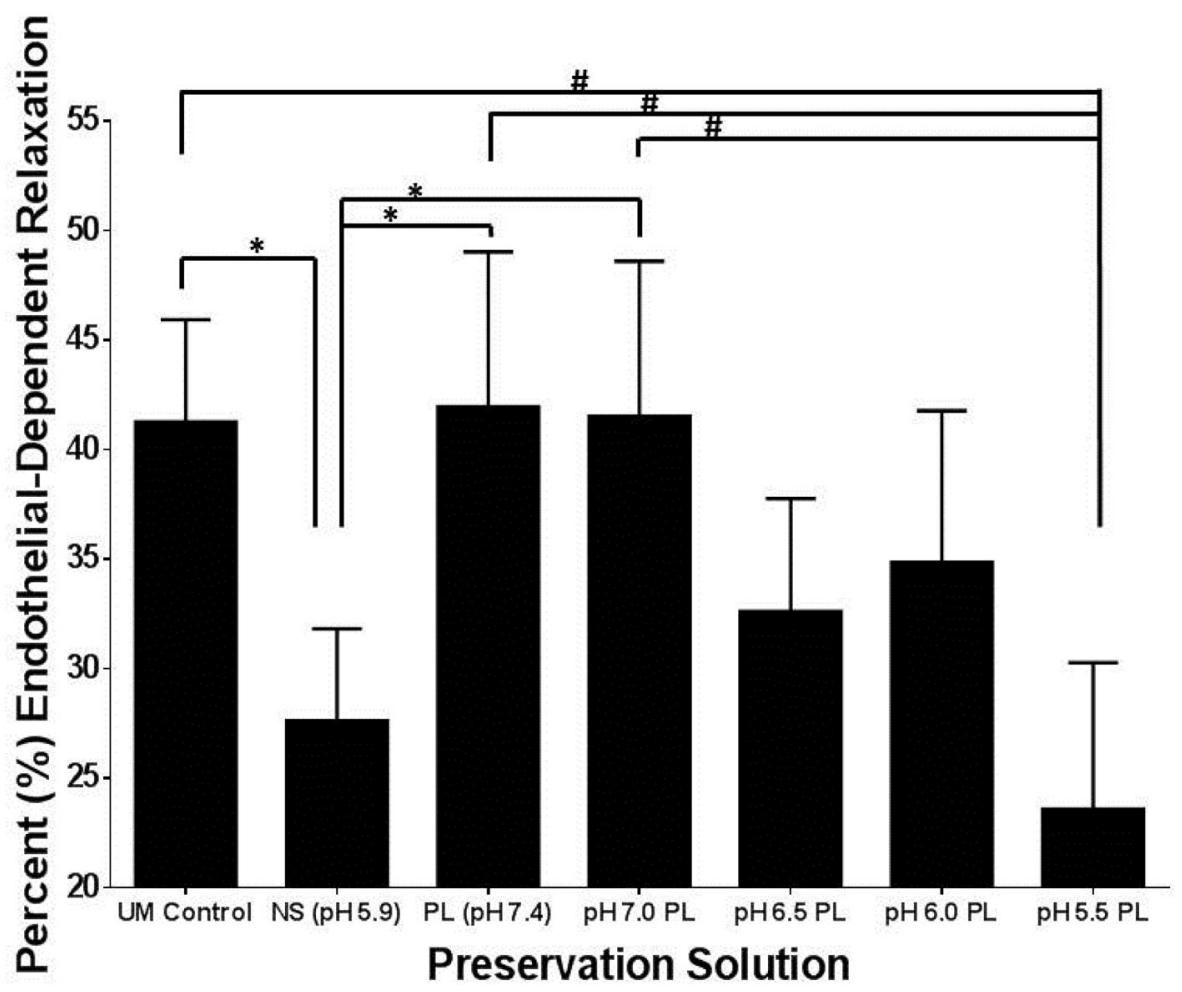

Figure 4.

Endothelial-Dependent Smooth Muscle Relaxation of Rat Aorta. Tissues preserved in normal saline or $\mathrm{pH}$ 5.5-Plasma-Lyte A demonstrated a decrement in endothelial function relative to UP control, and tissues preserved in Plasma-Lyte A or pH 7.0-PlasmaLyte A. $* P<.05$ relative to normal saline; ${ }^{\#} P<.05$ relative to $\mathrm{pH}-5.5$ PlasmaLyte A. Error bars represent standard error of the mean.

UP- Unprepared Control; PL- Plasma-Lyte A; NS- normal saline 
Table 1

Components of solutions assessed as HSV preservation media in our investigation

\begin{tabular}{|c|c|c|c|}
\hline Solution & $\begin{array}{l}\text { Stated pH (stated range) } \\
\text { Estimated Osmolarity }\end{array}$ & $\begin{array}{l}\text { Approximate Electrolyte } \\
\text { Composition }(\mathbf{m m o l} / \mathbf{L})^{\dagger}\end{array}$ & Additives $(\mathrm{mmol} / \mathrm{L}) *$ \\
\hline Plasma-Lyte A (Baxter) & $\begin{array}{l}7.4(6.5-8.0) \\
294 \mathrm{mOsm} / \mathrm{L}\end{array}$ & $\begin{array}{l}\text { Sodium- } 140 \\
\text { Potassium- } 5 \\
\text { Magnesium- } 3 \\
\text { Chloride- } 98 \\
\text { Acetate- } 27 \\
\text { Gluconate- } 23\end{array}$ & none \\
\hline $0.9 \%$ Normal Saline (Baxter) & $\begin{array}{l}5.0(4.5-7.0) \\
308 \mathrm{mOsm} / \mathrm{L}\end{array}$ & $\begin{array}{l}\text { Sodium- } 154 \\
\text { Chloride- } 154\end{array}$ & none \\
\hline University of Wisconsin Solution & $\begin{array}{c}7.4 \\
320 \mathrm{mOsm} / \mathrm{L}\end{array}$ & $\begin{array}{c}\text { Sodium- } 27 \\
\text { Potassium- } 125 \\
\text { Magnesium- } 5 \\
\text { Sulfate- } 5 \\
\text { Phosphates- } 25(\mathrm{mmol} / \mathrm{L})\end{array}$ & $\begin{array}{c}\text { Lactobionic Acid- } 105 \\
\text { Adenosine- } 5 \\
\text { Allopurinol- } 1 \\
\text { Raffinose- } 30 \\
\text { Glutathione- } 3 \\
\text { Polyhydroxyethyl starch- } 50 \mathrm{~g} / \mathrm{L}\end{array}$ \\
\hline Celsior Solution & $\begin{array}{c}7.3 \\
360 \mathrm{mOsm} / \mathrm{L}\end{array}$ & $\begin{array}{l}\text { Sodium- } 100 \\
\text { Potassium- } 15 \\
\text { Magnesium- } 13 \\
\text { Calcium- } 0.25 \\
\text { Chloride- } 42\end{array}$ & $\begin{array}{c}\text { Glutathione- } 3 \\
\text { Mannitol- 60 } \\
\text { Lactobionic Acid- } 80 \\
\text { Glutamic Acid- } 20 \\
\text { Histidine- } 30\end{array}$ \\
\hline Autologous Whole Blood & $\begin{array}{c}7.4 \\
280-310 \mathrm{mOsm} / \mathrm{L}\end{array}$ & $\begin{array}{l}\text { Sodium- } 140 \\
\text { Potassium- } 5 \\
\text { Magnesium- } 2 \\
\text { Calcium- } 5 \\
\text { Chloride- } 110 \\
\text { Bicarbonate- } 24 \\
\text { Sulfate- } 2 \\
\text { Phosphates- } 4\end{array}$ & $\mathrm{n} / \mathrm{a}$ \\
\hline GALA Solution & $\begin{array}{c}7.4 \\
309 \mathrm{mOsm} / \mathrm{L}\end{array}$ & $\begin{array}{l}\text { Sodium- } 142 \\
\text { Potassium- } 6 \\
\text { Magnesium- } 1 \\
\text { Calcium- } 1 \\
\text { Chloride- } 145 \\
\text { Bicarbonate- } 4 \\
\text { Phosphates- } 1 \text { (mmol/L) } \\
\text { Sulfate- } 0.5\end{array}$ & $\begin{array}{l}\text { Glutathione- } 1 \\
\text { L-Ascorbic Acid- } 0.5 \\
\text { L-Arginine- } 0.5 \\
\text { Glucose- } 6\end{array}$ \\
\hline \multicolumn{4}{|c|}{$\begin{array}{l}\text { Autologous whole blood composition varies among patients; } \\
\text { small quantities of bicarbonate and chloride were added to buffer University of Wisconsin solution, Celsior solution and GALA to pH } 7.4 \text {. } \\
\text { whole blood. } 40 \text { units/mL added to GALA. }\end{array}$} \\
\hline
\end{tabular}




\section{Table 2}

Physiologic Responses of HSV after 2 hour preservation in various media, relative to Unprepared (UP) control tissue.

\begin{tabular}{|c|c|c|c|c|}
\hline \multirow[b]{2}{*}{ Solution } & \multicolumn{2}{|c|}{ Vasoconstriction } & \multicolumn{2}{|c|}{ Vasorelaxation } \\
\hline & KCl (110 mM) & Phenylephrine (1-5 $\mu \mathrm{M})$ & $\begin{array}{l}\text { Endothelial-Independent ( } 0.1 \\
\mu M \text { sodium nitroprusside) }\end{array}$ & $\begin{array}{c}\text { Endothelial-dependent }(0.5 \\
\mu M \text { carbachol })\end{array}$ \\
\hline Plasma-Lyte A & $\leftrightarrow$ & $\leftrightarrow$ & $\leftrightarrow$ & $\downarrow$ \\
\hline Normal Saline & $\downarrow$ & $\downarrow$ & $\downarrow$ & $\downarrow$ \\
\hline University of Wisconsin & $\uparrow$ & $\uparrow$ & $\leftrightarrow$ & $\downarrow$ \\
\hline Celsior & $\uparrow$ & $\uparrow$ & $\leftrightarrow$ & $\leftrightarrow$ \\
\hline Autologous Whole Blood & $\downarrow$ & $\leftrightarrow$ & $\leftrightarrow$ & $\leftrightarrow$ \\
\hline GALA & $\leftrightarrow$ & $\uparrow$ & $\leftrightarrow$ & $\leftrightarrow$ \\
\hline
\end{tabular}

$\uparrow$ - increased response, $\leftrightarrow$ - similar response, $\downarrow$-decreased response, relative to UP control tissue at significance of $P \leq 05$ 